\title{
Nephrology
}

\section{Consequences of Inadequate Management of Hyponatremia}

\author{
Horacio J. Adrogué \\ Department of Medicine, Baylor College of Medicine and Methodist Hospital, and Renal Section, \\ Department of Veterans Affairs Medical Center, Houston, Tex., USA
}

\section{Key Words}

Hyponatremia • Vasopressin • Water excretion •

Salt-water balance

\begin{abstract}
Dilutional hyponatremia is a commonly observed disorder in hospitalized patients. It represents an excess of water in relation to prevailing sodium stores and is most often associated with a high plasma level of arginine vasopressin, including that found in patients with the syndrome of inappropriate antidiuretic hormone secretion. Hyponatremia may be classified as either acute or chronic depending on the rate of decline of serum sodium concentration, and can lead to a wide range of deleterious changes involving almost all body systems. Serious complications of dilutional hyponatremia most frequently involve the central nervous system. In fact, acute severe hyponatremia is potentially life-threatening and must be treated promptly and aggressively. Chronic hyponatremia often develops in patients with nonrenal diseases and is associated with increased morbidity and mortality. In patients hospitalized for congestive heart failure, hyponatremia is linked to a poor prognosis and increased length of hospital stay. Prompt recognition and optimal management of hyponatremia in hospital-
\end{abstract}

ized patients may reduce in-hospital mortality and symptom severity, allow for less intensive hospital care, decrease the duration of hospitalization and associated costs, and improve the treatment of underlying comorbid conditions and patients' quality of life. The proper treatment of dilutional hyponatremia, especially when chronic, must avoid increasing serum sodium too rapidly, which can lead to permanent or fatal neurologic sequelae. The treatment of hyponatremia may be facilitated by emerging therapies that block the actions of arginine vasopressin at $\mathrm{V}_{2}$ and $\mathrm{V}_{1 \mathrm{a}}$ receptors to promote aquaresis, the electrolyte-sparing elimination of free water, and elevate serum sodium concentrations.

Copyright $(2005$ S. Karger AG, Basel

\section{Introduction}

The concentration of sodium in plasma is maintained within a relatively narrow range by homeostatic mechanisms involving thirst, arginine vasopressin (AVP, also called antidiuretic hormone), and renal control of water excretion. Changes in any of the key elements that control water balance can lead to hyponatremia, a commonly observed condition that most often has small clinical expression but can significantly increase morbidity and the risk

\section{KARGER \\ Fax +41613061234 E-Mail karger@karger.ch} www.karger.com
(C) 2005 S. Karger AG, Basel 0250-8095/05/0253-0240\$22.00/0

Accessible online at: www.karger.com/ajn
Horacio J. Adrogué, MD

Section of Nephrology, Baylor College of Medicine

6550 Fannin, SM 1273

Houston, TX 77030 (USA)

Tel. +1 713798 8350, Fax +1 713790 5053, E-Mail hadrogue@bcm.tcm.edu 
of death, as well as complicate the course of concurrent disease. This brief review addresses the dominant form of hyponatremia and the importance of appropriate treatment.

\section{Hyponatremia: Definition, Incidence, and Pathophysiology}

Hyponatremia is defined as a decrease in the serum sodium concentration $\left(\left[\mathrm{Na}^{+}\right]\right.$) to $<136$ (normal range $136-148) \mathrm{mEq} / 1[1]$. This disorder is commonly observed, occurring in up to $6 \%$ of hospitalized patients [2]. It is important to distinguish osmolality from tonicity. Osmolality is a function of the total concentration of solutes (largely ions) in a solution, and this measure does not depend on whether the solutes can cross cell membranes. Tonicity or effective osmolality refers to the osmotic gradient due to solutes that do not cross the cell membrane.

Dilutional hyponatremia, by far the most common form of the disorder, is caused by excessive water retention. If water intake exceeds the excretory capacity of the kidneys, then sodium dilution occurs, resulting in hypoosmolality, hypotonicity, and hyponatremia [1]. This syndrome develops when the ingestion or infusion of fluids continues in the presence of persistent antidiuretic activity, almost always due to elevated plasma AVP. For example, patients with the syndrome of inappropriate antidiuretic hormone secretion (SIADH) will continue to drink despite having hypotonic hyponatremia, since the inhibitory effect of osmoregulated thirst is not sufficiently strong to stop drinking behavior [3].

A number of conditions and medications are associated with hyponatremia, and specific factors that increase the risk for this condition have been identified, including surgery or injury, very young or old age, renal dysfunction, adrenal insufficiency, hypothyroidism, cirrhosis, congestive heart failure (CHF), and central nervous system (CNS) impairment [4-6]. Drugs associated with an increased risk for the development of hyponatremia include thiazide diuretics, desmopressin, oxytocin, prostaglandin synthesis inhibitors, nicotine, phenothiazines, tricyclic antidepressants, selective serotonin reuptake inhibitors, opiate derivatives, chlorpropamide, clofibrate, carbamazepine, cyclophosphamide, and vincristine [1].

There are also several types of nonhypotonic hyponatremia, including hypertonic hyponatremia, isotonic hyponatremia, and pseudohyponatremia. Hypertonic hyponatremia is caused by a shift of water from inside cells to the extracellular space and is driven by solutes confined to the extracellular compartment. This disorder may be associated with hyperglycemia or the retention of hypertonic mannitol. Isotonic hyponatremia, which is caused by the retention of large amounts of isotonic fluid (e.g., isotonic mannitol), occurs without any transmembrane shift in water. The term 'pseudohyponatremia' describes a falsely low serum $\left[\mathrm{Na}^{+}\right]$measurement, which occurs, as in cases of extreme hyperlipidemia or hyperproteinemia, when serum $\left[\mathrm{Na}^{+}\right]$is measured by flame photometry or indirect potentiometry $[1,7]$.

Dilutional hyponatremia is most often associated with excessive AVP secretion, especially in SIADH. This syndrome is caused by the aberrant or sustained secretion of AVP in the absence of an appropriate stimulus (elevated plasma osmolality). Elevated AVP secretion leads to water retention by the kidney. In patients with SIADH, AVP release is not suppressed when plasma osmolality falls below the normal threshold for the stimulation of AVP secretion $[8,9]$.

AVP exerts its effects on water balance by promoting free water absorption in the distal tubule of the nephron. AVP binds to the $\mathrm{V}_{2}$ receptor, activating adenyl cyclase and promoting cyclic adenosine monophosphate (cAMP) production. Cyclic AMP stimulates protein kinase A (PKA), which phosphorylates aquaporin-2. Phosphorylation leads to the insertion of aquaporin-2 into the apical plasma membrane, allowing water to be reabsorbed. Water is then removed to the peritubular capillaries and the systemic circulation by aquaporin-3 or 4 . When AVP is removed from its receptor, aquaporin-2 is internalized, thereby reducing the osmotic water permeability $[10,11]$. In normal states, escape from antidiuresis is accompanied by the downregulation of both aquaporin and $\mathrm{V}_{2}$ receptors in the kidney $[12,13]$. In pathologic states, such as SIADH, CHF, and cirrhosis, AVP is elevated and there is a direct relationship between an increased AVP concentration and reduced water excretion [14]. In patients with these conditions and AVP excess, water intake exceeding $800 \mathrm{ml} /$ day leads to water retention and, in turn, the dilution of all fluid compartments, including the intravascular compartment, which leads to hyponatremia [15].

Osmoregulated AVP release can be measured from the changes in plasma AVP that occur in response to the infusion of hypertonic saline. This procedure has been used to identify 4 patterns of AVP secretion in patients who have SIADH [3]. In the most common pattern (occurring in about $40 \%$ of patients with SIADH), AVP release is excessive and erratic and totally unrelated to plasma os- 
molality. In the second most common pattern $(\sim 30 \%$ of patients), referred to as 'reset osmostat', AVP release continues to regulate water excretion but at a lower plasma osmolality set point. In the third pattern, which is rare in malignant disease, the control of AVP secretion is absent at low plasma osmolality, but the osmoregulation of AVP is otherwise normal. In the last pattern, which occurs in a small number of patients, the osmoregulation of AVP secretion is normal even as SIADH is evident [3].

SIADH may arise in response to a wide range of conditions, including small cell lung cancer, head trauma (e.g., subdural hematoma, subarachnoid hemorrhage, or intracranial hemorrhage), and pulmonary infections (table 1) [16]. A number of drugs may also cause SIADH and hyponatremia, including tricyclic antidepressants, selective serotonin reuptake inhibitors, conventional and atypical antipsychotics (e.g., haloperidol and risperidone) $[17,18]$, narcotics, angiotensin-converting enzyme (ACE) inhibitors, sulfonylureas used in the treatment of type-2 diabetes, thiazide diuretics, and antineoplastic agents (vincristine, vinblastine, cyclophosphamide) [16].

SIADH is also a common complication of pituitary surgery, possibly secondary to damage to the hypothalamic-pituitary tract [19]. The SIADH associated with neurologic trauma or surgery is usually not associated with inadequate glucocorticoid replacement and may be iatrogenic [19]. The synthesis and release of AVP are also increased chronically in patients with heart failure. In advanced CHF, low cardiac output leads to low blood pressure, which is sensed by baroreceptors that stimulate further AVP secretion to increase vascular resistance and water retention in the kidney [9].

The prevalence of hyponatremia increases with age, and several studies have documented a high prevalence of SIADH in the elderly population $[16,20]$. In fact, in a longitudinal assessment of nursing home residents $>60$ years of age, $53 \%$ had at least 1 episode of hyponatremia during a 12-month follow-up period. The most common cause of hyponatremia in these patients was SIADH [16], which is frequently observed in hospitalized patients [20].

Hyponatremia may be classified as acute or chronic. This distinction is relevant, as the rate at which hyponatremia develops significantly influences the severity of CNS manifestations and potential complications [1, 18]. Acute severe hyponatremia occurs when serum $\left[\mathrm{Na}^{+}\right]$ falls rapidly below $120 \mathrm{mEq} / \mathrm{l}$ in less than $48 \mathrm{~h}$. Because homeostatic mechanisms in the brain cannot react with sufficient speed to compensate for this rapid change, acute severe hyponatremia, if untreated, can lead to ce-
Table 1. Potential causes of SIADH and hyponatremia

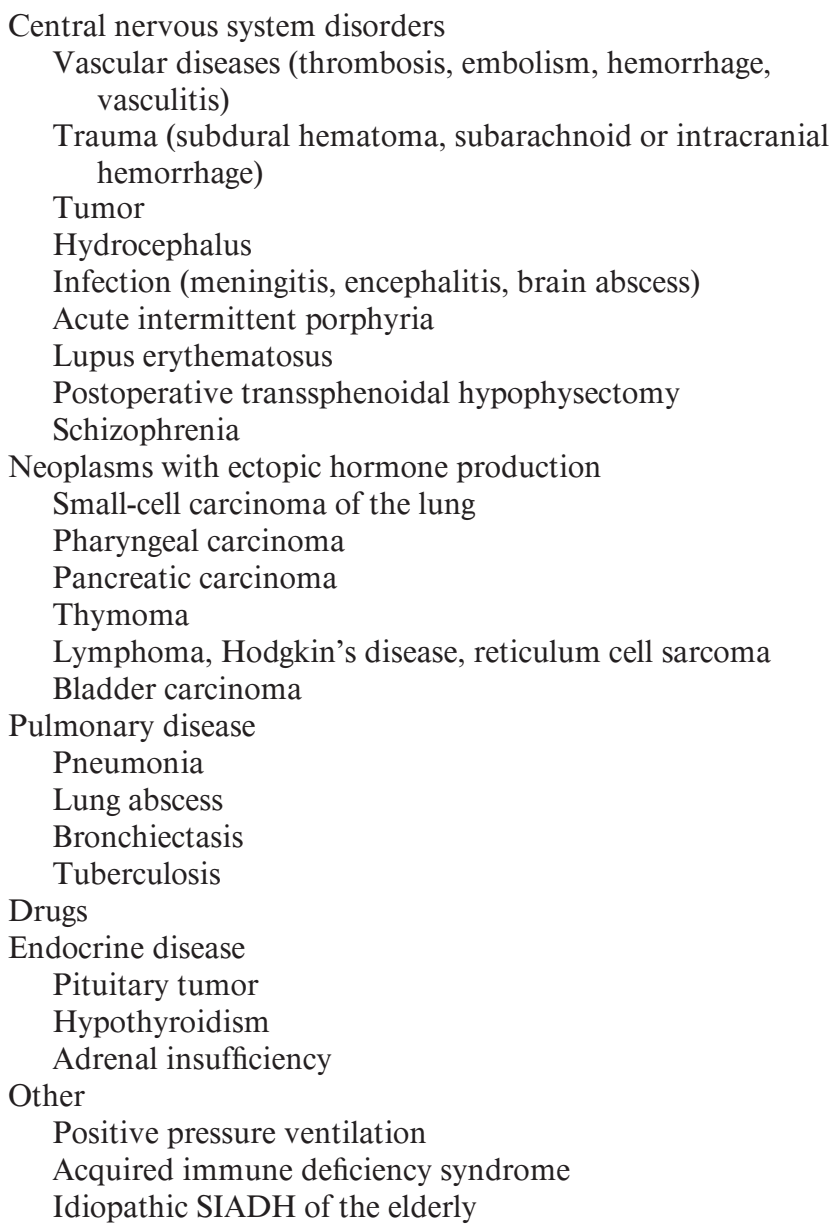

Positive pressure ventilation

Acquired immune deficiency syndrome

Idiopathic SIADH of the elderly

Adapted with permission from Miller [16].

rebral edema, irreversible neurologic damage, respiratory arrest, brainstem herniation, and even death $[1,21]$. In contrast, mild chronic hyponatremia is most often asymptomatic. Symptoms usually do not arise until the serum $\left[\mathrm{Na}^{+}\right]$falls below $120 \mathrm{mEq} / \mathrm{l}$, and they are initially nonspecific (e.g., headache, lethargy, nausea). As hyponatremia becomes more severe, neurologic and gastrointestinal symptoms appear. The risk of seizures increases as the $\left[\mathrm{Na}^{+}\right]$continues to fall [22].

Chronic hyponatremia occurs when serum $\left[\mathrm{Na}^{+}\right]$falls slowly during a period of $48 \mathrm{~h}$ or more. In this case, the brain can compensate to a considerable extent for falling sodium levels by the cellular exit of organic solutes that promote water loss and ameliorate brain swelling. This adaptation by the brain can minimize the symptoms dur- 
ing chronic hyponatremia, but paradoxically, it may increase the risk for the development of osmotic demyelination $[1,21]$. Osmotic demyelination appears to be caused by shrinkage of the brain associated with aggressive treatment of hyponatremia. This shrinkage leads to demyelination of pontine and extrapontine neurons and may result in neurologic dysfunction, paralysis, pseudobulbar palsy, seizures, coma, and even death [1].

At present, there is no clear consensus regarding the optimal treatment of symptomatic hyponatremia. Some have recommended the pace of correction be sufficient to reverse the manifestations of hypotonicity but not so rapid as to risk osmotic demyelination. The rate of correction should be approximately $8 \mathrm{mEq} / \mathrm{l} / \mathrm{day}$; when the symptoms are severe, the initial rate should be $1-2 \mathrm{mEq} / \mathrm{l} / \mathrm{h}$ [1]. Although the benefits of prompt and aggressive treatment of hyponatremia have been demonstrated, it is important to remember that overly rapid correction of symptomatic hyponatremia can lead to central pontine myelinolysis and significant permanent neurologic deficits [23]. Nevertheless, the importance of slow correction to avoid neurologic problems must be weighed against the significantly improved survival rate that is associated with more rapid correction, particularly among patients hospitalized with severe hyponatremia [24].

\section{Medical Consequences of Hyponatremia}

Hyponatremia can produce a wide range of disturbances involving almost all body systems, but the most relevant and potentially lethal involve the CNS. As noted above, acute severe hyponatremia, if left untreated, causes cerebral edema that can lead to coma, irreversible neurologic damage, and even death [1, 21]. In contrast, mild chronic hyponatremia is most often asymptomatic. Symptoms usually do not arise until the serum $\left[\mathrm{Na}^{+}\right]$falls below $120 \mathrm{mEq} / \mathrm{l}$, and they are initially nonspecific (e.g., headache, lethargy, nausea). As hyponatremia becomes more severe, neurologic and gastrointestinal symptoms appear. The risk of seizures increases as serum $\left[\mathrm{Na}^{+}\right]$continues to fall [22]. Neurologic symptoms associated with severe chronic hyponatremia include lethargy, hemiplegia, seizures, limb weakness, dysarthria, hallucinations, tremor, acute psychosis, and coma. Patients may also demonstrate a positive Babinski's sign [25, 26]. Hyponatremia worsens the prognosis of heart and renal failure and increases mortality in hospitalized patients [2729].

Management of Hyponatremia

\section{Consequences of Hyponatremia and Potential Benefits of Optimal Treatment}

\section{Impact of Hyponatremia on Patient Outcomes and Treatment Costs}

Hyponatremia that is not promptly and effectively treated can negatively impact outcomes associated with chronic disease, most notably in patients with CHF. Whether hyponatremia is an independent risk factor for death or is simply associated with other conditions that significantly raise the risk of death remains to be elucidated [29]. However, results from one large-scale clinical cohort study suggest that hyponatremia is an independent risk factor for in-hospital mortality. Terzian et al. [30] studied the occurrence of admission hyponatremia and its relationship with treatment outcome in a cohort of 4,123 geriatric patients; these authors showed that in-hospital mortality was $16.0 \%$ among patients with admission hyponatremia, versus $8.0 \%$ among those admitted without this condition. The prevalence of hyponatremia at the time of hospital admission was 3.5\% (4.6\% in women and $2.6 \%$ in men). A logistic regression analysis showed that hyponatremia at the time of hospital admission was a significant independent predictor of mortality (relative risk 1.95) [30].

In a retrospective study, Nzerue et al. [24] assessed severe hyponatremia (serum $\left[\mathrm{Na}^{+}\right]<115 \mathrm{mEq} / \mathrm{l}$ ) in 168 hospitalized patients, focusing on factors involved in the development, treatment, and outcomes of this condition. Among patients with severe hyponatremia, 52.9\% were symptomatic and the overall mortality was $20.2 \%$. A multivariate analysis indicated that hypoxia, neurologic symptoms, sepsis, and a slow correction of serum $\left[\mathrm{Na}^{+}\right]$ were all strongly associated with death in this cohort. The serum $\left[\mathrm{Na}^{+}\right]$after $48 \mathrm{~h}$ of treatment was $127.1 \mathrm{mEq} / \mathrm{l}$ in survivors versus $118.8 \mathrm{mEq} / \mathrm{l}$ in patients who died $(\mathrm{p}=$ 0.0016). These results, like those of Terzian et al. [30], suggest that prompt correction of serum $\left[\mathrm{Na}^{+}\right]$may significantly improve short-term survival among patients hospitalized with severe hyponatremia [24].

A prospective study of 435 patients admitted to a university hospital with evidence of CHF also points to hyponatremia as an important determinant of treatment outcomes and costs among hospitalized patients. In multivariate analyses of these patients, a serum $\left[\mathrm{Na}^{+}\right]$ $\leq 135 \mathrm{mEq} / \mathrm{l}$ was a significant and independent predictor ( $p \leq 0.01$ ) of major complication or death during hospitalization; $25 \%$ of patients with a serum $\left[\mathrm{Na}^{+}\right]$of $\leq 135 \mathrm{mEq} / \mathrm{l}$, versus $15 \%$ of those whose serum sodium level was $>135 \mathrm{mEq} / \mathrm{l}$, experienced a major complication 
or died in the hospital. In addition, a serum $\left[\mathrm{Na}^{+}\right]$of $\leq 135 \mathrm{mEq} / \mathrm{l}$ was significantly and independently associated with an increased duration of hospital stay and higher hospital cost ( $p \leq 0.01$ for both) [31].

The increased length of hospital stay in patients with hyponatremia was demonstrated in another retrospective analysis of 1,046 patients hospitalized for heart failure ( $58 \%$ older than 65 years). In this study, 171 patients had hyponatremia (serum $\left[\mathrm{Na}^{+}\right]<135 \mathrm{mEq} / \mathrm{l}$ ) at admission and their mean length of stay was 5.78 versus 4.72 days among patients without hyponatremia $(p=0.0001)$. The only variable other than hyponatremia that was associated with a longer duration of hospitalization was admission from a skilled nursing facility (6.22 days). Multivariate linear regression analysis indicated that hyponatremia was a significant predictor of hospitalization duration in this cohort of patients [32].

\section{Hyponatremia in the Emergency Department}

Hyponatremia is a very relevant electrolyte disorder among people who present to the emergency department (ED). In an analysis of 3,784 ED patients, $0.4 \%$ had hyponatremia (serum $\left[\mathrm{Na}^{+}\right]<134 \mathrm{mEq} / \mathrm{l}$ ) and $65 \%$ of those patients exhibit signs of depletion of extracellular fluid volume. Almost all cases of hyponatremia had recognizable causes involving the gastrointestinal $(24.1 \%)$, urogenital $(17.2 \%)$, respiratory $(15.1 \%)$, hematopoietic $(9.0 \%)$, cardiovascular $(6.2 \%)$, musculoskeletal $(5.5 \%)$, endocrine (5.5\%), or CNS (2.4\%). Only $2.7 \%$ of the cases of hyponatremia reviewed in this analysis were iatrogenic. The overall mortality among patients with hyponatremia was $17.9 \%$, which was higher among those with lower sodium levels but was not significantly related to gender, age, cause, or serum potassium levels [33].

In an evaluation by VillaCorta et al. [34], 170 elderly patients were admitted to the ED with decompensated heart failure and followed up for an average period of 14 months after discharge. In these patients, hyponatremia was associated with significantly increased mortality risk (hazard ratio $=2.0, p=0.009$ ) [34]. Brophy et al. [35] reported very similar results in a study of 153 consecutive patients presenting to the ED with decompensated heart failure and followed up for an average of 44 months afterward. The overall survival rate for these patients was low: $61 \%$ died during the follow-up period. In multivariate analysis using the Cox proportional hazards model, hyponatremia was a significant predictor of mortality (relative risk $=2.1, \mathrm{p}=0.005$ ) and patients with hyponatremia who were treated with ACE inhibitors were at the greatest risk for death (relative risk $=11.5, \mathrm{p}<0.001$ )
The poor prognosis among patients with hyponatremia who used ACE inhibitors was thought to reflect the inability of these drugs to normalize high renin levels often associated with this condition [35].

Given the clear relationship between hyponatremia and poor outcomes among patients admitted to the ED, it is reasonable to suggest that prompt treatment of hyponatremia may improve outcome, decrease the risk of death, and permit patients to spend fewer days in the hospital and undergo less expensive treatment.

\section{Impact of Prompt Treatment on Underlying Comorbid Conditions}

The prompt correction of hyponatremia in patients who present with comorbid disease, such as CHF or psychosis, is associated with significantly improved longterm outcomes. Licata et al. [36] compared the effects of a combination of high-dose furosemide and small-volume hypertonic saline solution infusion with those of a bolus of high-dose furosemide alone in a randomized, single-blind study that included 107 patients with refractory New York Heart Association (NYHA) class-IV CHF. In patients given furosemide alone, serum $\left[\mathrm{Na}^{+}\right]$was reduced from 134.8 to $130.2 \mathrm{mEq} / 1(\mathrm{p}<0.007)$, while the level in patients who received furosemide plus hypertonic saline solution increased from 135.7 to $142.3 \mathrm{mEq} / 1$ $(p<0.001)$. The between-group difference in serum $\left[\mathrm{Na}^{+}\right]$ was associated with a substantial difference in survival during a 4-year follow-up period (fig. 1). The survival rate among patients who received furosemide plus hypertonic saline solution was 55 versus $13 \%$ among those treated with furosemide alone. These results suggest that the treatment of hyponatremia has a positive impact on longterm survival in patients with severe CHF [36]. It is important to note that not all patients with hyponatremia and CHF may benefit from hypertonic saline solution therapy. In a small study of 5 patients with dominating right heart failure, 3 patients experienced weight gain (1$2 \mathrm{~kg}$ ) and a recurrence of hyponatremia [37].

Life-threatening water intoxication may occur in individuals with schizophrenia, who may have polydipsia that is accompanied by overhydration and dilutional hyponatremia. If the hyponatremia is not effectively treated, the symptoms may progress from mild confusion to acute delirium, seizures, coma, and even death [38]. Furthermore, the risk of hyponatremia in patients with psychosis is increased by treatment with fluoxetine, tricyclic antidepressants, or calcium channel blockers [39].

Exacerbations of psychosis are associated with enhanced AVP secretion in patients who have schizophre- 


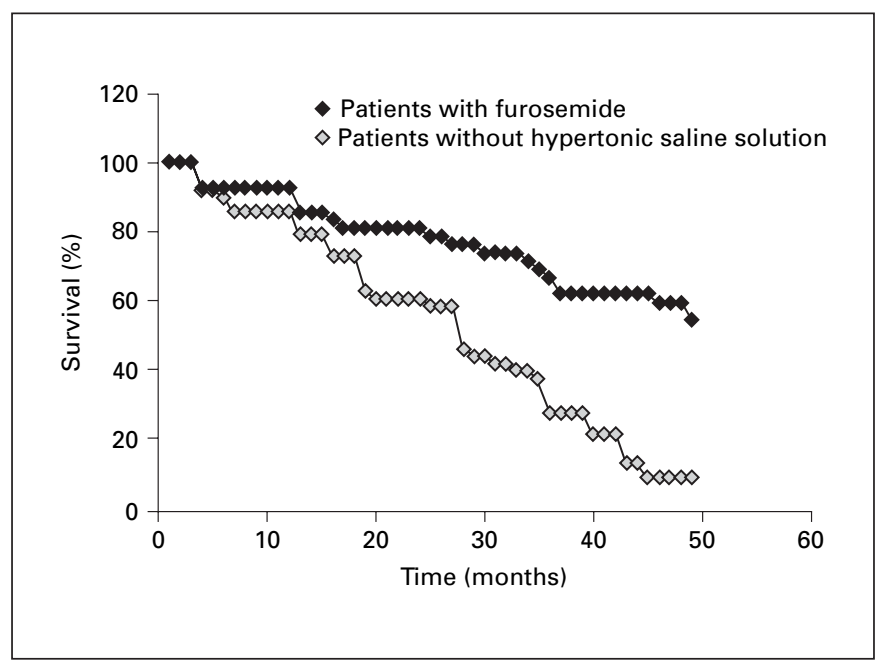

Fig. 1. Kaplan-Meier survival analysis among patients with $\mathrm{CHF}$ given furosemide with and without hypertonic saline solution. Adapted with permission from Licata et al. [36].

nia, polydipsia, and hyponatremia; such a combination may lead to more severe symptoms of psychosis than does polydipsia without hyponatremia. In a small-scale study of patients with psychosis and polydipsia with and without hyponatremia, those with hyponatremia had higher (i.e., worse) scores on the Brief Personality Rating Scale (total and positive and negative symptom scores) and exhibited much greater symptom exacerbation after methylphenidate challenge (i.e., stimulant administration that reliably induces transient psychotic exacerbations in patients with schizophrenia, even those receiving neuroleptic therapy) than did patients without hyponatremia [40].

\section{Consequences of Inappropriate Treatment of \\ Hyponatremia}

At present, there is no consensus regarding the optimal treatment of symptomatic hyponatremia. Current recommendations suggest the pace of correction be sufficient to reverse the manifestations of hypotonicity but not so rapid as to create significant risk for osmotic demyelination. The rate of correction should be $8 \mathrm{mEq} / \mathrm{l} / \mathrm{day}$; for patients with severe symptoms, the initial rate should be 1-2 mEq/ $1 / h$. These limits may be exceeded with caution when the risks associated with continued hypotonicity are greater than those of osmotic demyelination. Thus, although the benefits of prompt and aggressive treatment of hyponatremia have been demonstrated, it is important to re-

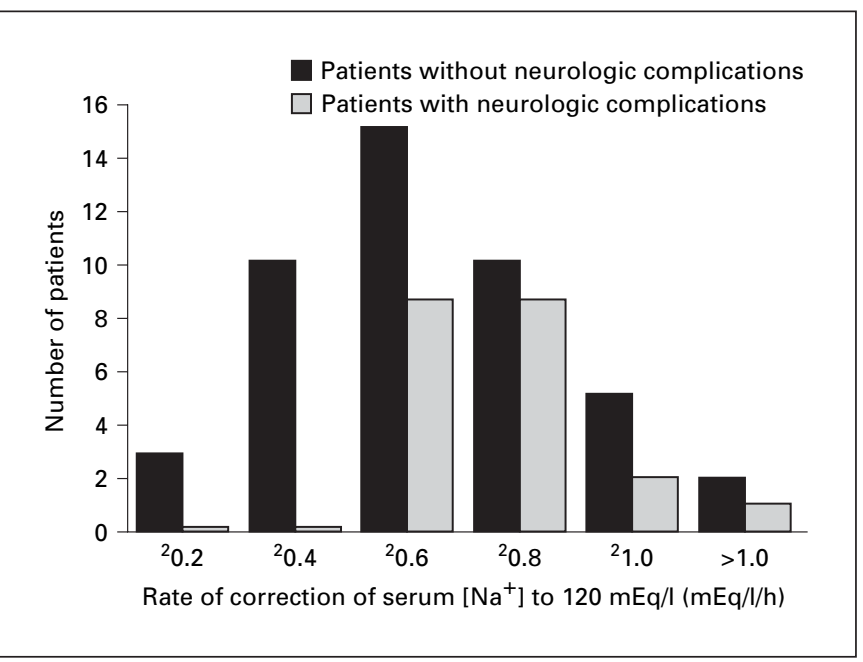

Fig. 2. Outcomes for 52 cases of hypotonic hyponatremia. Neurologic complications were associated with higher rates of sodium correction. Adapted with permission from Sterns [23].

member that overly rapid correction of symptomatic hyponatremia can lead to osmotic demyelination and significant permanent neurologic deficits [23].

In a retrospective analysis of 62 patients with severe hyponatremia (serum $\left[\mathrm{Na}^{+}\right]<110 \mathrm{mEq} / \mathrm{l}$ ) who presented to 1 of 2 hospitals during a 5-year period, 7 patients demonstrated delayed neurologic sequelae that became apparent several days after their initial symptoms of hyponatremia had resolved and their serum $\left[\mathrm{Na}^{+}\right]$had increased to $>120 \mathrm{mEq} / 1$. This pattern was most evident in patients who underwent the most rapid correction of serum $\left[\mathrm{Na}^{+}\right](>0.55 \mathrm{mEq} / \mathrm{l} / \mathrm{h}$; fig. 2) [41].

In another study, Tanneau et al. [42] examined the progress of 12 patients with psychogenic polydipsia who experienced a total of 24 episodes of symptomatic hyponatremia (serum $\left[\mathrm{Na}^{+}\right] \leq 115 \mathrm{mEq} / \mathrm{l}$ ) during a 10 -year period. Seven patients recovered from a total of 19 episodes of symptomatic hyponatremia without significant complications. Five patients had delayed neurologic sequelae, and 3 of these patients had symptoms characteristic of central pontine myelinolysis (seizures, dysarthria, vertigo, parkinsonism, quadriparesis, diffuse spastic hypertonia, pseudobulbar palsy, confusion, and coma). One patient died, 1 had severe motor dysfunction that remained 7 years after the event, and 1 recovered completely [42]. In reviewing the treatment of hyponatremia in patients who did and did not experience neurologic complications, the investigators found that patients who 


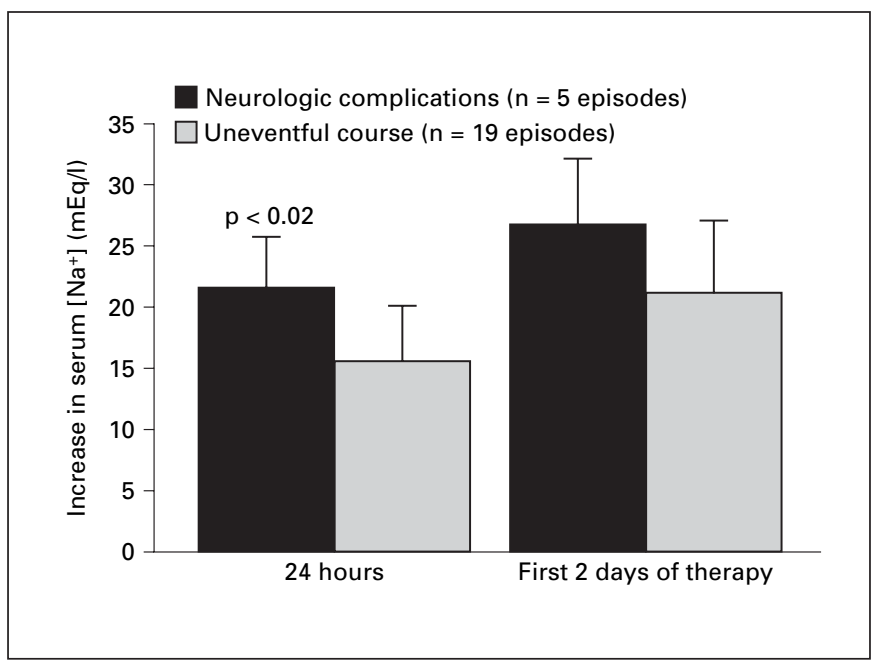

Fig. 3. Maximal increase in serum $\left[\mathrm{Na}^{+}\right]$during $24 \mathrm{~h}$ and magnitude of correction over 2 days in 12 patients with and without neurologic complications. Adapted with permission from Tanneau et al. [42].

had such sequelae had a higher maximal 24-hour increase in serum $\left[\mathrm{Na}^{+}\right](21.8$ vs. $15.5 \mathrm{mEq} / \mathrm{l}$, respectively; $\mathrm{p}<$ 0.02; fig. 3). Tanneau et al. [42] concluded that a large rapid increase in serum $\left[\mathrm{Na}^{+}\right]$may be detrimental in patients with chronic hyponatremia. These results are consistent with those obtained from a survey of the American Society of Nephrology that evaluated the treatments and outcomes among patients who presented with serum $\left[\mathrm{Na}^{+}\right] \leq 105 \mathrm{mEq} / \mathrm{l}$. Fourteen of these patients demonstrated post-therapeutic neurologic sequelae, the occurrence of which was significantly associated with a serum $\left[\mathrm{Na}^{+}\right]$correction rate of $\geq 0.55 \mathrm{mEq} / \mathrm{l} / \mathrm{h}$ and $\geq 12 \mathrm{mEq} / \mathrm{l} /$ day [43].

The potential consequences of overly rapid correction of hyponatremia are clear and underscore the importance of monitoring the rate of correction carefully to avoid permanent and potentially fatal neurologic complications. Nevertheless, the importance of slow correction to avoid neurologic problems must be weighed against the significantly improved survival rate that is associated with more rapid correction, particularly among patients hospitalized with severe hyponatremia [24].

\section{Effective Treatment of Hyponatremia Has the}

Potential to Improve Patients' Quality of Life

Two studies have demonstrated that effective treatment of hyponatremia can significantly benefit patients' overall health, which may brighten the quality of life. In the previously mentioned study by Licata et al. [36], effective treatment of hyponatremia in patients with $\mathrm{CHF}$ resulted in the reduced frequency and severity of dyspnea, lower limb edema, weakness, and fatigue. Moreover, patients whose hyponatremia was effectively corrected in this study typically improved from NYHA functional class IV to class II [36]. These benefits might be expected to enhance those patients' quality of life through relief of pulmonary congestion and reduced need for more aggressive treatments. Similar improvements may be observed when the treatment of polydipsia and psychosis also includes the correction of hyponatremia [44]. The possible cause-effect relationship between effective treatment of hyponatremia and quality of life warrants further study.

\section{New Approaches to the Treatment of Hyponatremia}

Current treatment for hyponatremia depends primarily on the underlying cause and can include, in addition to water restriction, sodium supplementation (with or without hypertonic saline) and diuretic therapy [22]. The effects of these measures may be undermined by poor patient compliance, however, and the serum $\left[\mathrm{Na}^{+}\right]$must be monitored closely to ensure the correction is not too rapid $[22,45]$. One alternative is the tetracycline antibiotic demeclocycline (600-1200 mg/day), which induces renal AVP resistance and diabetes insipidus, both of which lead to a modest increase in urine volume, decreased urine osmolality, and a corresponding rise in serum $\left[\mathrm{Na}^{+}\right]$. The clinical utility of this agent may be limited by its renal and hepatic toxic effects, however [22].

Because hyponatremia associated with water retention is a result of excess AVP, the most rational approach to therapy for this disorder is to either decrease the secretion of AVP or block its effects in the kidney [9]. The direct approach involves antagonizing the AVP receptors specifically. There are three AVP-receptor subtypes, $\mathrm{V}_{1 \mathrm{a}}, \mathrm{V}_{2}$, and $V_{3}$ (fig. 4). The $V_{1 a}$ receptor is $G$ protein-coupled and exerts its effects via the phosphoinositide pathways. It is expressed by vascular smooth muscle cells and regulates vascular smooth muscle tone. The $\mathrm{V}_{2}$ receptor is also $\mathrm{G}$ protein-coupled and, as noted above, exerts its effects via cAMP-related pathways. This receptor is expressed in the kidney and may also be present in the vascular endothelium. The $\mathrm{V}_{3}$ receptor is expressed by cells in the anterior pituitary and is involved in the regulation of corticotropin release [10]. 
Fig. 4. Distribution and actions of different AVP receptor subtypes. Reproduced with permission from Ferguson et al:: Clin Sci 2003;105:1-8. (C) The Biochemical Society.

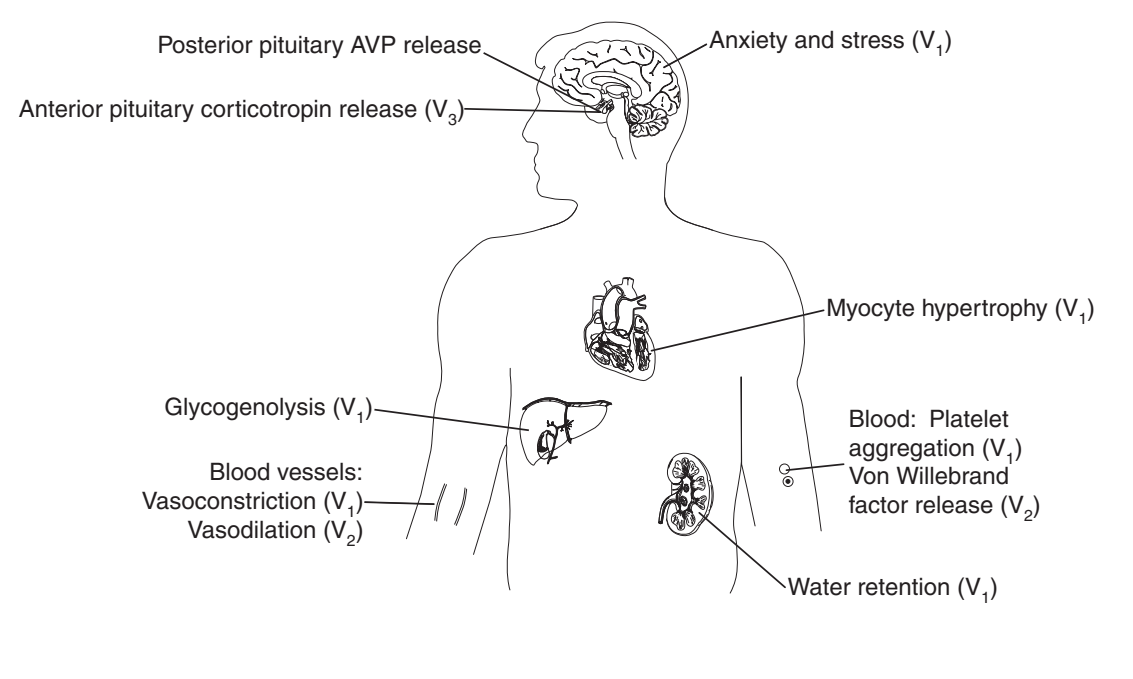

Selective AVP-receptor blockade can be effective for a number of conditions, including hyponatremia and CHF [10, 15, 46, 47], and may have significant advantages over traditional therapies. For example, in patients with CHF, AVP antagonism can reduce congestion effectively without worsening renal function, potassium depletion, or hypotension, a problem often associated with diuretic treatment [47].

$\mathrm{V}_{2}$-receptor-selective agents have been evaluated in both animal experimental and clinical studies, and several drugs in this class are currently in development. Lixivaptan, an orally active $\mathrm{V}_{2}$-receptor antagonist, produced a significant response in patients with hyponatremia, increasing free water clearance and serum $\left[\mathrm{Na}^{+}\right]$in accordance with the dosage given [48]. Tolvaptan, a nonpeptide $\mathrm{V}_{2}$-selective AVP-receptor antagonist, when coadministered with furosemide, increased serum $\left[\mathrm{Na}^{+}\right]$ significantly in patients with CHF [49]. SR121463, a third $\mathrm{V}_{2}$-selective $\mathrm{AVP}$-receptor antagonist, has produced dose-dependent aquaresis in healthy human volunteers and in animal models of hyponatremia, but it has yet to be evaluated in clinical trials [50].

Conivaptan is an AVP-receptor antagonist active at both $\mathrm{V}_{1 \mathrm{a}}$ and $\mathrm{V}_{2}$ receptors and is the only dual-receptor antagonist that has been evaluated extensively in clinical trials [51]. In 1 randomized, double-blind, multicenter, placebo-controlled, parallel-group study, 85 patients with euvolemic or hypervolemic hyponatremia were assigned to either placebo or an initial 20-mg loading dose of conivaptan followed by a continuous infusion of either
40 or $80 \mathrm{mg} /$ day for 4 days. Both conivaptan doses were significantly more effective than placebo in increasing serum $\left[\mathrm{Na}^{+}\right]$and effective water clearance, a measure of electrolyte-free water excretion [52]. In 2 other studies, 83 and 74 patients, respectively, with euvolemic or hypervolemic hyponatremia were given 40 or $80 \mathrm{mg}$ /day conivaptan or placebo for 5 days. In both trials, conivaptan improved the area under the serum $\left[\mathrm{Na}^{+}\right]$time curve and all secondary measures of efficacy significantly more than placebo $[53,54]$.

\section{Conclusions}

Hyponatremia is the most common electrolyte disorder in clinical medicine and is often a consequence of excess AVP secretion and edema-forming disorders such as CHF. This dysnatremia occurs frequently among both inpatients and outpatients. Acute severe hyponatremia is a life-threatening event that demands prompt and aggressive treatment. Chronic hyponatremia also significantly complicates patient care and is associated with increased morbidity and mortality. Low serum sodium in patients hospitalized for CHF is associated with a poor prognosis and increased length of hospital stay. Hyponatremia can also exacerbate psychiatric symptoms in patients exhibiting psychosis and polydipsia. Rapid recognition and optimal treatment of depressed serum sodium can reduce the risk of death and symptom severity, permit less intensive care, reduce the duration of hospitalization and as- 
sociated costs, increase success in treatment of underlying comorbid conditions, and improve quality of life. The treatment of chronic hyponatremia must be undertaken with care to avoid too rapid increases in serum sodium concentration and potentially permanent and even dead- ly neurologic sequelae. New therapies for the treatment of hyponatremia, particularly AVP-receptor antagonists, may help clinicians to safely correct this disorder and improve outcomes among a wide range of patients.

\section{References}

$\checkmark 1$ Adrogué HJ, Madias NE: Hyponatremia. N Engl J Med 2000;342:1581-1589.

$\checkmark 2$ Han D-S, Chu B-S: Therapeutic approach to hyponatremia. Nephron 2002;92(suppl 1):913.

-3 Baylis PH: The syndrome of inappropriate antidiuretic hormone secretion. Int $\mathrm{J}$ Biochem Cell Biol 2003;35:1495-1499.

4 Palmer BF: Hyponatremia in patients with central nervous system disease: SIADH versus CSW. Trends Endocrinol Metab 2003;14:182187.

5 Palmer BF, Gates JR, Lader M: Causes and management of hyponatremia. Ann Pharmacother 2003;37:1694-1702.

-6 Clark BA, Shannon RP, Rosa RM, Epstein FH: Increased susceptibility to thiazide-induced hyponatremia in the elderly. J Am Soc Nephrol 1994;5:1106-1111.

7 Weisberg LS: Pseudohyponatremia. Am J Med 1989;86:315-318.

-8 Verbalis JG: Vasopressin $\mathrm{V}_{2}$ receptor antagonists. J Mol Endocrinol 2002;29:1-9.

-9 Wong LL, Verbalis JG: Vasopressin $\mathrm{V}_{2}$ receptor antagonists. Cardiovasc Res 2001;51:391402.

10 Ferguson JW, Therapondos G, Newby DE, Hayes PC: Therapeutic role of vasopressin receptor antagonism in patients with liver cirrhosis. Clin Sci 2003;105:1-8.

-11 Nielsen S, Kwon T-H, Christensen BM, Promeneur D, Froklaer J, Marples D: Physiology and pathophysiology of renal aquaporins. J Am Soc Nephrol 1999; 10:647-663.

12 Ecelbarger CA, Chou CL, Lee AJ, DiGiovanni SR, Verbalis JG, Knepper MA: Escape from vasopressin-induced antidiuresis: Role of vasopressin resistance of the collecting duct. Am J Physiol 1998;274:F1161-F1166.

13 Tian Y, Sandberg K, Murase T, Baker EA, Speth RC, Verbalis JG: Vasopressin $\mathrm{V}_{2}$ receptor binding is down-regulated during renal escape from vasopressin-induced antidiuresis. Endocrinology 2000;141:307-314.

14 Camps J, Sola J, Arroyo V, Perez-Ayuso RM, Gaya J, Rivera F, Rodes J: Temporal relationship between the impairment of free water excretion and antidiuretic hormone hypersecretion in rats with experimental cirrhosis. Gastroenterology 1987;93:498-505.

15 Palm C, Gross P: V2-vasopressin receptor antagonists-mechanism of effect and clinical implications in hyponatraemia. Nephrol Dial Transplant 1999;14:2559-2562.
16 Miller M: Syndromes of excess antidiuretic hormone release. Crit Care Clin 2001;17:1123.

17 Peck V, Shenkman L: Haloperidol-induced syndrome of inappropriate secretion of antidiuretic hormone. Clin Pharmacol Ther 1979; 26:442-444.

18 Whitten JR, Ruehter VL: Risperidone and hyponatremia: A case report. Ann Clin Psychiatry 1997;9:181-183.

19 Casulari LA, Costa KN, Albuquerque RC, Naves LA, Suzuki K, Domingues L: Differential diagnosis and treatment of hyponatremia following pituitary surgery. J Neurosurg Sci 2004;48:11-18.

20 Kinzie BJ: Management of the syndrome of inappropriate secretion of antidiuretic hormone. Clin Pharm 1987;6:625-633.

-21 Soupart A, Decaux G: Therapeutic recommendations for management of severe hyponatremia: Current concepts on pathogenesis and prevention of neurologic complications. Clin Nephrol 1996;46:149-169.

22 Goh KP: Management of hyponatremia. Am Fam Physician 2004;69:2387-2394.

23 Sterns RH: The treatment of hyponatremia: First do no harm. Am J Med 1990;88:557560.

24 Nzerue CM, Baffoe-Bonnie H, You W, Falana B, Dai S: Predictors of outcome in hospitalized patients with severe hyponatremia. J Natl Med Assoc 2003; 95 :335-343.

25 Ellis SJ: Severe hyponatremia: Complications and treatment. Q J Med 1995;88:905-909.

26 Arieff AI, Llach F, Massry SG: Neurological manifestations and morbidity of hyponatremia: Correlation with brain water and electrolytes. Medicine (Baltimore) 1976;55:121129.

27 Lee DS, Austin PC, Rouleau JL, Liu PP, Naimark D, Tu JV: Predicting mortality among patients hospitalized for heart failure: Derivation and validation of a clinical model. JAMA 2003;290:2581-2587.

28 Packer M, Lee WH, Kessler PD, Medina N, Yushak M, Gottlieb SS: Identification of hyponatremia as a risk factor for the development of functional renal insufficiency during converting enzyme inhibition in severe chronic heart failure. J Am Coll Cardiol 1987;10:837844.

29 Fried LF, Palevsky PM: Hyponatremia and hypernatremia. Med Clin North Am 1997;81: 585-609.
30 Terzian C, Frye EB, Piotrowski ZH: Admission hyponatremia in the elderly: Factors influencing prognosis. J Gen Intern Med 1994;9: 89-91.

-31 Chin MH, Goldman L: Correlates of major complications or death in patients admitted to the hospital with congestive heart failure. Arch Intern Med 1996;156:1814-1820.

32 Krumholz HM, Chen YT, Bradford WD, Cerese J: Variations in and correlates of length of stay in academic hospitals among patients with heart failure resulting from systolic dysfunction. Am J Manag Care 1999;5:715-723.

-33 Lee CT, Guo HR, Chen JB: Hyponatremia in the emergency department. Am J Emerg Med 2000; 18:264-268.

- 34 VillaCorta H, Mesquita ET, Cardoso R, Bonates T, Maia ER, Silva ACM, Guimarâes MAP, Dohmann HJF: Emergency department predictors of survival in decompensated heart failure patients (in Portuguese). Rev Port Cardiol 2003;22:495-507.

-35 Brophy JM, Deslauriers G, Rouleau JL: Longterm prognosis of patients presenting to the emergency room with decompensated congestive heart failure. Can J Cardiol 1994; 10:543547.

36 Licata G, Di Pasquale P, Parrinello G, Cardinale A, Scandurra A, Follone G, Argano C, Tuttolomondo A, Paterna S: Effects of highdose furosemide and small-volume hypertonic saline solution infusion in comparison with a high dose of furosemide as bolus in refractory congestive heart failure: Long-term effects. Am Heart J 2003;145:459-466.

37 Forssell G, Nordlander R, Orinius E: Treatment of dilutional hyponatremia in congestive heart failure. Acta Med Scand 1980;207:279281.

38 Cosgray RE, Hanna V, Davidhizar RE, Smith $\mathrm{J}$ : The water-intoxicated patient. Arch Psychiatr Nurs 1990;4:308-312.

-39 Siegler EL, Tamres D, Berlin JA, Allen-Taylor L, Strom BL: Risk factors for the development of hyponatremia in psychiatric inpatients. Arch Intern Med 1995;155:953-957.

- 40 Goldman MB, Robertson GL, Luchins DJ, Hedeker D, Pandey GN: Psychotic exacerbations and enhanced vasopressin secretion in schizophrenic patients with hyponatremia and polydipsia. Arch Gen Psychiatry 1997;54:443449 . 
41 Sterns RH: Severe symptomatic hyponatremia: Treatment and outcome. Ann Intern Med 1987; 107:656-664.

-42 Tanneau RS, Henry A, Rouhart F, Bourbigot B, Garo B, Mocquard Y, Goas J-Y: High incidence of neurologic complications following rapid correction of severe hyponatremia in polydipsic patients. J Clin Psychiatry 1994;55: 349-354.

-43 Sterns RH, Cappuccio JD, Silver SM, Cohen EP: Neurologic sequelae after treatment of severe hyponatremia: A multicenter perspective. J Am Soc Nephrol 1994;4:1522-1530.

44 Leadbetter RA, Shutty MS Jr, Higgins PB, Pavalonis D: Multidisciplinary approach to psychosis, intermittent hyponatremia, and polydipsia. Schizophr Bull 1994;20:375-385.

$\checkmark 4$ DeCaux G, Soupart A: Treatment of symptomatic hyponatremia. Am J Med Sci 2003;326: 25-30.
46 Palm C, Reimann D, Gross P: The role of V2 vasopressin antagonists in hyponatremia. Cardiovasc Res 2001;51:403-408.

47 Lee CR, Watkins ML, Patterson JH, Gattis W, O'Connor CM, Gheorghiade M, Adams KF Jr: Vasopressin: A new target for the treatment of heart failure. Am Heart J 2003;146:9-18.

48 Wong F, Blei AT, Blendis LM, Thuluvath PJ: A vasopressin receptor antagonist (VPA-985) improves serum sodium concentration in patients with hyponatremia: A multicenter, randomized, placebo-controlled trial. Hepatology 2003; 37:182-191.

49 Gheorghiade M, Niazi I, Ouyang J, Czerwiec F, Kambayashi J, Zampino M, Orlandi C: Vasopressin $\mathrm{V}_{2}$-receptor blockade with tolvaptan in patients with chronic heart failure: Results from a double-blind, randomized trial. Circulation 2003;107:2690-2696.
50 Serradeil-Le Gal C: An overview of SR121463, a selective non-peptide vasopressin $\mathrm{V}_{2}$ receptor antagonist. Cardiovasc Drug Rev 2001;19: 201-214.

51 Martinez-Castelao A: Conivaptan (Yamanouchi). Curr Opin Investig Drugs 2002;3:89-95.

52 Verbalis JG, Smith N: Novel vasopressin $\mathrm{V}_{1 \mathrm{~A}}$ and $\mathrm{V}_{2}$ antagonist (conivaptan) increased serum sodium concentration and effective water clearance in patients with hyponatremia (abstract 3346). Circulation 2004; 110 (suppl III): III-723.

53 Gross P, Smith N: Conivaptan, a novel $\mathrm{V}_{1 \mathrm{~A}}$ and $V_{2}$ antagonist, increased serum sodium and effective water clearance in patients with hyponatremia clinical trial (abstract 3345). Circulation 2004;110(suppl III):III-723.

54 Ghali JK, Smith N: Efficacy of the vasopressin $\mathrm{V}_{1 \mathrm{~A}} / \mathrm{V}_{2}$ antagonist conivaptan in patients with euvolemic or hypervolemic hyponatremia (abstract 3347). Circulation 2004; 110 (suppl III): III-723. 